\title{
Fiğ Üretiminde Farklı Toprak İşleme-Ekim Yöntemlerinin Özgül Çeki Gücü, Yakıt Tüketimi ve İş Başarısına Etkisi
}

\author{
Zinnur GÖZÜBÜYÜK ${ }^{1 *}$ \\ Taner YILDIZ ${ }^{4}$, \\ Ahmet ÇELÍ ${ }^{2}$, \\ Gazanfer ERGÜNEŞ ${ }^{3}$,

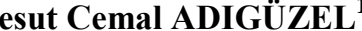 \\ ${ }^{1}$ Doğu Anadolu Tarımsal Araştırma Enstitüsü, Erzurum, Türkiye \\ ${ }^{2}$ Atatürk Üniversitesi, Ziraat Fakültesi, Tarım Makinaları ve Teknolojileri Mühendisliği Bölümü, Erzurum, Türkiye \\ ${ }^{3}$ Gaziosmanpaşa Üniversitesi, Ziraat Fakültesi, Biyosistem Mühendisliği Bölümü, Tokat, Türkiye \\ ${ }^{4}$ Ondokuz Mayıs Üniversitesi, Samsun Meslek Yüksekokulu, Makina ve Metal Teknolojileri Bölümü, \\ Tarım Makinaları Programı, Samsun, Türkiye \\ (*Sorumlu yazar: e-mail: zgozubuyuk2001@yahoo.com)
}

DOI: 10.17097/ataunizfd.379103

Geliş Tarihi: 15.01.2018

Kabul Tarihi: 20.04.2018

\begin{abstract}
ÖZ: Bu çalışma, Erzurum yöresi sulu ve kuru tarım koșullarında, dokuz yıl süren geleneksel münavebe periyodunda yer alan fiğ üretiminde dört farklı toprak işleme-ekim yönteminin önemli bazı işletme parametrelerine etkilerinin belirlenmesi amaciyla gerçekleştirilmiştir. Toprak işleme-ekim yöntemleri; geleneksel toprak işleme (kulaklı pulluk+diskli tırmık (sulu)/kültivatör (kuru)+kombikrüm+ ekim makinası), azaltılmış toprak işleme-1 (kültivatör+kombikrüm+ekim makinası), azaltılmıș toprak işleme-2 (dik rotovatör+ekim makinası) ve doğrudan ekimden (doğrudan ekim makinası) oluşmuştur. Kuru tarım koşullarında özgül çeki kuvveti, özgül çeki gücü ve yakıt tüketiminin sulu koşullara göre daha yüksek, makina-insan işgücü gereksinimlerinin ise düşük olduğu belirlenmiştir. Yöntemler arasında en yüksek özgül çeki kuvveti geleneksel, en düşük değer ise doğrudan ekim yönteminden elde edilmiştir. Özgül çeki gücü ise tarla trafiğine paralel olarak artmış, geleneksel yöntemde en yüksek değerler elde edilmiştir. Sulu ve kuru tarım koşullarında toprak işleme-ekim için birim zamanda işlenen alan geleneksel yöntemde 0.13 ha $\mathrm{h}^{-1}$ olurken, doğrudan ekim yönteminde $12 \mathrm{~kat}$ daha fazla $\left(1.60 \mathrm{ha} \mathrm{h}^{-1}\right)$ olmuştur. Makina iş gücü yönünden geleneksel yöntemde $8.17 \mathrm{~h} \mathrm{ha}^{-1}$ zamana ihtiyaç duyulurken, doğrudan ekim yönteminde 5 kat daha az $\left(1.63 \mathrm{~h} \mathrm{ha}^{-1}\right)$ zamana ihtiyaç olduğu belirlenmiştir.
\end{abstract}

Anahtar kelimeler: Özgül çeki kuvveti, özgül çeki gücü, işletme değerleri, fiğ, geleneksel toprak işleme, doğrudan ekim

\section{Effect of Different Soil Tillage and Seeding Methods on Specific Draft Power, Fuel Consumption and Effective Field Capacity in Vetch Production}

\begin{abstract}
This study was conducted with the aim of determining the effects of four different tillage-seeding methods on some operational parameters in vetch production of nine years traditional rotation period under the irrigated and rainfed farming conditions in Erzurum. The tillage-seeding methods were traditional tillage method ((moldboard plough + disc harrow + combined harrows + seeder), reduced tillage method-1 (cultivator + combined harrows + seeder), reduced tillage method-2 (rotary power harrow + seeder) and direct drilling (no-till seeder)) method. Under rainfed farming conditions specific draft force, specific draft power and fuel consumption were higher and machine-human labor was lower than those determined under irrigated farming conditions The highest and lowest specific draft powers were found for traditional tillage and direct drilling methods, respectively. The specific draft power was increased parallel to field traffic and the highest specific draft power was found for traditional tillage method. The tilled acreage per unit time were $0.13 \mathrm{ha} \mathrm{h}^{-1}$ and $1.60 \mathrm{ha} \mathrm{h}^{-1}$ for traditional tillage method and direct drilling method, respectively. In terms of machine time required, $8.17 \mathrm{~h} \mathrm{ha}^{-1}$ is needed in traditional tillage method and $1.63 \mathrm{~h} \mathrm{ha}{ }^{-1}$ in direct drilling method.
\end{abstract}

Key words: Specific draft force, specific draft power, operational parameters, vetch, traditional tillage, direct drilling

\section{GİRIŞ}

Tarımsal işlemler arasında, toprak şartları çok iyi bir durumda olsa bile tüm tarımsal üretim işlemleri içinde toplam güç tüketimi yönünden toprak işleme \%60'llk paya sahiptir (Lazic ve Turan, 1995; Aase ve Schaefer, 1996). Bu nedenle, toprak işleme maliyet yönünden bitkisel üretimde en pahalı işlemdir. Tahıl üretimi için gerekli çalışma süresinin yarıdan fazlasının toprak işleme ve tohum yatağ hazırlamada kullanılması ve bunun da ürün verimine $\% 25$ 'e ulaşan oranlarda etki yapması, tarımsal üretimde toprak hazırlama işlemlerine ayrıcalıklı bir önem kazandırmıştır (Eker ve Ülger, 1988). Toprak işleme ile ürün veriminin artırılması veya eşdeğer ürünün daha az maliyetle elde edilmesi düşüncesi, azaltılmış toprak işleme ve toprak işlemesiz tarım konularını ön plana çıkarmıştır (Özgüven, 1993). Alternatif toprak işleme yöntemleri ve alınacak diğer önlemler sonucunda toprak işleme maliyetinin \%3050 oranında azaltılabileceği ifade edilmektedir (Zeren, 1991).

Griffith ve Parson (1981) yaptıkları araştırmada, geleneksel toprak işleme yöntemine göre azaltılmış toprak işleme ve toprak işlemesiz doğrudan anıza ekim yönteminin, büyük ölçüde zaman ve yakıt tasarrufu sağladığı belirlenmiştir. Ayrıca, toprak ve nem korunumu, bitki kök gelişimi ve boşluk hacminde üstünlüklerinin olduğu ve ürün verimi açısından yöntemler arasında çok fazla farklılık olmamasına karşın geleneksel yönteme göre diğer iki yöntemin daha ekonomik olduğu belirtilmiştir. 
Toprak işleme, tarımsal üretimdeki iş zinciri içerisinde en fazla güç ve zaman gereksinimine neden olan işlemdir. Günümüzdeki enerji dar boğazı tüm sektörlerde olduğu gibi, tarımda da enerji tasarrufu sağlayacak ve amaca daha kısa zaman içerisinde ulaşılabilecek yolların aranmasını zorunlu duruma getirmiştir. Ülkemizde işlenen alanların büyüklüğü yanında uygulanan toprak işleme-ekim yöntemleri göz önüne alındığında enerji tutumu ve zaman kazancı sağlayan yöntemlerin uygulamaya sokulmasının ekonomimize önemli katkıda bulunacağı açıkça görülmektedir. Bu da tarımsal işler içerisinde özellikle toprak işleme-ekim için en ekonomik ve etkili yöntemleri seçmek ve uygulamaya aktarmakla mümkündür (Gökçebay, 1983).

Özsert ve Kara (1987) tarafindan, kuru tarım tahıl üretiminde uygulanmakta olan kara nadas, kimyasal nadas, geleneksel toprak işleme, azaltılmış toprak işleme ve doğrudan ekim sistemleri çok yönlü olarak incelenmiştir. İşgücü gereksinimleri, geleneksel toprak işlemede \%100 alındığında, azaltılmış toprak işlemede \%76 seviyesinde ve doğrudan ekim ise \%39 seviyesinde bulunmuştur. Yakıt tüketimleri ise sirasıyla 48.4, 34.8 ve $31.0 \mathrm{~L}$ ha ${ }^{1}$ olarak belirlenmiştir.

Kasap vd. (1989) tarafindan yapılan bir çalışmada, geleneksel toprak işleme yöntemine göre doğrudan ekim yönteminde $33.1 \mathrm{~L} \mathrm{ha}^{-1}$, çizelin kullanıldığ1 yöntemde ise $23.1 \mathrm{~L} \mathrm{ha}^{-1}$ daha az yakıt tüketilmiştir. Doğrudan ekimde bir taraftan enerji tasarrufu sağlanırken, diğer taraftan erozyon $\% 90$ oranında azalmakta, toprak yüzeyindeki artık maddeler toprak nemini korumakta, zaman ve işçilikten tasarruf sağlamaktadır.

Sungur vd. (1994), yaptıkları bir araştırmada, değişik toprak işleme yöntemlerinde, yakıt tüketimi açısından dik rotavatör ve kültivatörün kullanıldığ 1 konuların en uygun sonuçları verdiğini, ancak doğrudan ekim konusunun yakıt ve zaman yönünden en avantajlı yöntem olduğunu belirtmişlerdir. Anonim (2011), geleneksel uygulamada birim alandan (ha) ortalama 63.2 litre yakıt tüketimi olurken, azaltılmış toprak işlemede 22.8 litre, doğrudan ekimde ise 10 litreye kadar düşmektedir.

Konya bölgesinde anızı yakılan tarla koşullarında yürütülen bir araştırmada, buğday tarımında kullanılan farklı toprak işleme yöntemlerinin toprağın fiziksel özelliklerine, yakıt tüketimine ve dane verimine etkisi araştırılmıştır. Yapılan bu çalışmada, kulaklı pulluk+iki kez diskaro, iki kez rototiller, pulluk gövdecikli kültivatör + ağır tip goble disk ve iki kez ağır goble disk olmak üzere dört farklı toprak işleme yöntemi kullanılmıştır. Araştırma sonuçlarına göre; yakıt tüketimi pullukta 19.25 $\mathrm{L} \mathrm{ha}^{-1}$, diskaroda $5.74 \mathrm{~L} \mathrm{ha}^{-1}$, rototillerde 13.4 $\mathrm{L}$ ha $^{-1}$ bulunmuştur. Yöntemlerin toplam yakıt tüketimleri ise sirasiyla $30.73,26.8,18.25$ ve $20.31 \mathrm{~L}$ ha $^{-1}$ olarak belirlenmiştir (Çarman vd., 1995).

Dünya genelinde toprak işlemesiz tarım alanı 1999 yılında 45 milyon hektar iken 10 y1l sonra 111 milyon hektara ulaşmış, hızla artarak günümüzde yaklaşık olarak 155 milyon hektarlık alana ulaşmıştır (FAO, 2014). Doğrudan ekim yaygın olarak ABD, Brezilya, Kanada, Şili, Paraguay, Avustralya ve bazı gelişmiş ülkelerde yaygın olarak yapılırken, ülkemizde 45000 hektar düzeyindedir (FAO AQUASTAT,2014).

Doğrudan ekim yöntemi, dünyanın birçok ülkesinde deniz seviyesinden 3000 m'lik rakıma kadar ve yılda $250 \mathrm{~mm}$ yağış alan kuru tarım koşulları ile 2000 veya $3000 \mathrm{~mm}$ yağış alan alanlarda uygulanabilir (Derpsch vd., 2010).

Toprağın ve diğer doğal kaynakların sürdürülebilirliği açısından tarım sektöründe alınabilecek önlemlerin başında kıt olan yenilenemez kaynakların daha verimli kullanılması, daha az enerji ile eşdeğer ürünün elde edilmesi gelmektedir. $\mathrm{Bu}$ çalışma, geleneksel münavebe uygulamaları dikkate alınarak; sulu tarım koşullarında (fiğ +buğday+ayçiçeği) ve kuru tarım koşullarında (fiğ+buğday+nadas) üç yılda bir ekilen fiğ üretiminde geleneksel uygulamanın yerini alabilecek koruyucu toprak işleme ve doğrudan ekim uygulamalarının, özgül çeki kuvveti-çeki gücü ve bazı işletme değerleri açısından karşılaştırılarak, en uygun yöntemin belirlenmesi amacıyla yapılmıştır.

\section{MATERYAL VE METOT}

Araştırma, Erzurum-Pasinler ovasında denizden $1721 \mathrm{~m}$ yükseklikte yer alan Erzurum Doğu Anadolu Tarımsal Araştırma Enstitüsü Pasinler İstasyonu deneme alanlarında yağışa dayalı ve sulu koşullarda yürütülmüştür $\left(39.99^{\circ} \mathrm{N}, 41.57^{\circ} \mathrm{E}\right)$ (Şekil 1).
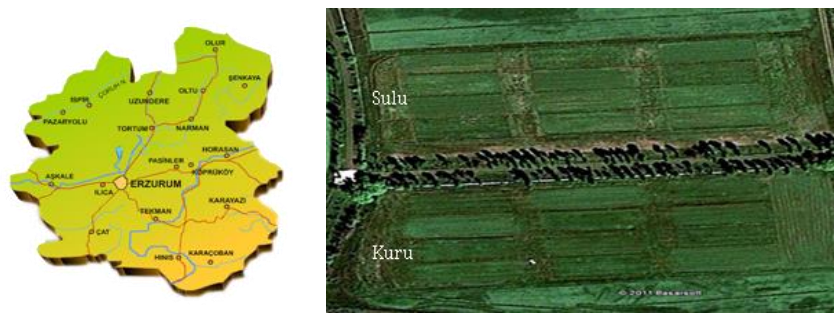

Şekil 1. Deneme yeri ve alanları 
Denemelerin yürütülmesinde $50 \mathrm{~kW}$ gücünde ve $3396 \mathrm{~kg}$ ağırlığında olan Massey Ferguson-365 S (çift çeker) traktör ile birlikte pulluk, diskli tırmık, ağır kültivatör, kombikrüm, dik rotovatör, diskli ve çapa ayaklı doğrudan ekim makinası kullanılmıştır. Kullanılan aletlerin teknik özellikleri Çizelge 1'de verilmiştir.

Çakılı olarak 1999-2008 yılları arasında (9 yıl) yürütülen çalışma, tesadüf blokları deneme planına göre üç tekerrürlü olarak düzenlenmiştir. Denemede suluda; fiğ, buğday ve ayçiçeği, kuruda ise; fiğ, buğday ve nadas'tan oluşan üçlü münavebe esas alınmıştır. $15 \times 40 \mathrm{~m}^{2}$ 'lik parsellerde yürütülen denemelerde uygulanan toprak işleme-ekim yöntemleri; geleneksel toprak işleme $\left(\mathrm{S}_{1}\right.$, kulaklı pulluk+diskli tırmık (sulu koşullarda)-kültivatör (kuru koşullarda)+kombikrüm + ekim makinası), azaltılmış toprak işleme-1 $\left(\mathrm{S}_{2}, \quad\right.$ kültivatör+ kombikrüm+ekim makinası), azaltılmış toprak işleme-2 $\left(S_{3}\right.$, dik rotovatör + ekim makinası) ve doğrudan ekimden $\left(S_{4}\right.$, doğrudan ekim makinası) oluşmuştur (Şekil 2).

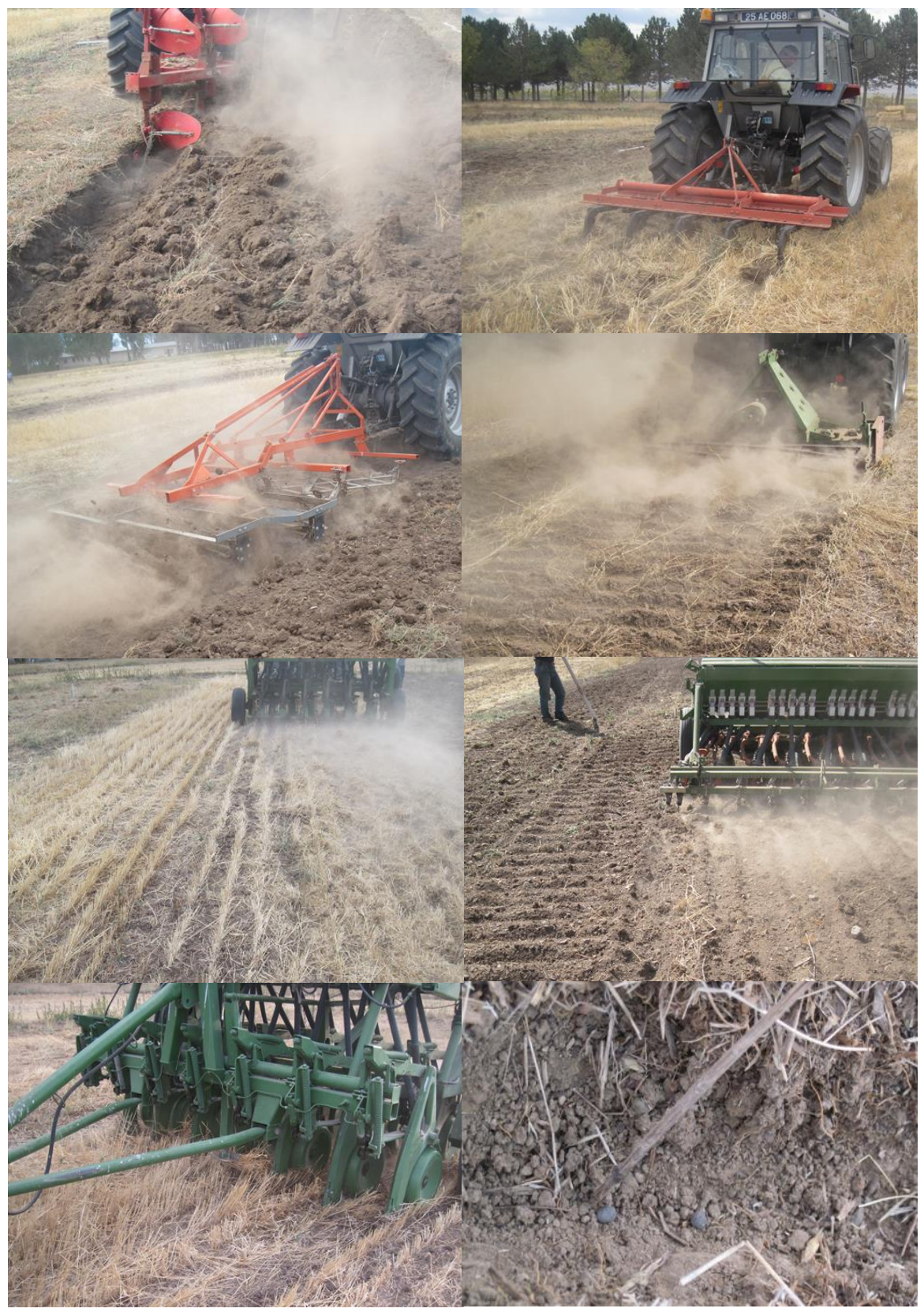

Şekil 2. Toprak işleme-ekim makinalarının çalışma görüntüleri 
Çizelge 1. Denemede kullanılan alet ve makinaların teknik özellikleri

\begin{tabular}{|c|c|c|c|c|c|c|c|}
\hline Teknik özellikler & 兰 & 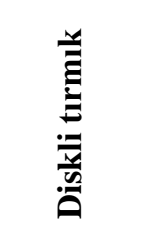 & 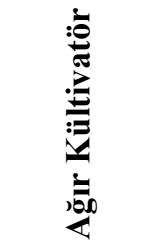 & 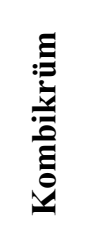 & 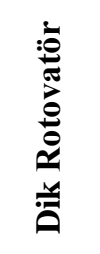 & 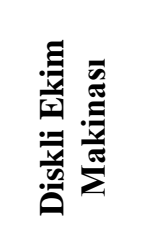 & 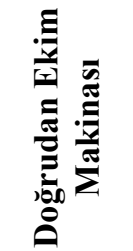 \\
\hline Tipi & Kulaklı & Tandem & - & - & - & Diş. mak & NT-250 \\
\hline İş genişliği, mm & 900 & 2100 & 2100 & 2200 & 2000 & 3000 & 2500 \\
\hline İș derinliği, mm & 260 & 113.1 & 139.3 & 71.1 & 117 & 61.5 & 62.2 \\
\hline 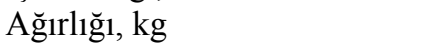 & 440 & 420 & 430 & 440 & 510 & 372 & 1400 \\
\hline Batarya sayısı, adet & - & 4 & - & - & 8 & - & - \\
\hline İşleyici ayak-sayısı, disk adet & 2 & 24 & 9 & - & - & 21 & 13 \\
\hline Ayak tipi & - & - & Kazayağı & - & - & Diskli & Çapa \\
\hline Biçak yüksekliği, mm & - & - & - & - & 16 & - & - \\
\hline Sıra arası mesafe, mm & - & - & - & - & - & 142.8 & 192 \\
\hline Tohum sandığ kapasitesi, L & - & - & - & - & - & 400 & 350 \\
\hline Gübre sandığı kapasitesi, L & - & - & - & - & - & - & 350 \\
\hline
\end{tabular}

\section{Güç Değerleri}

Denemede kullanılan tarım alet ve makinalarının özgül çeki gücü ve özgül çeki kuvveti, traktör üç nokta askı kollarına özel flanşlarla yerleştirilen kuvvet sensörleri yardımıyla; gerçek hız, traktöre monte edilen hız radarı ve traktör tekerleğine $120^{\circ}$ lik açıyla monte edilen patinaj sensörleri ile; gerçek yakıt tüketimi ise, yakıt deposu ile pistonlar arasına ve geri dönüşümleri de pompa ile yakıt deposu arasına yerleştirilen özel olarak tasarlanmış
$\% 1 \mathrm{ml}$ hassasiyetle ölçüm yapabilen elektronik yakıt ölçüm sayacı ile belirlenmiştir (Şekil 3). Ölçülen veriler veri depolama ünitesinde anlamlı verilere dönüştürülerek değerlendirilmiştir. Çalışmada, kullanılan bütün alet ve makinaların gerçek iş derinlikleri ile iş genişlikleri her parselden üçer tekerrürlü olarak ölçülmüsşür. Ölçülen bu iş genişliği ile iş derinliği verileri özgül çeki kuvveti ve çeki gücünün belirlenmesinde kullanılmıştır.

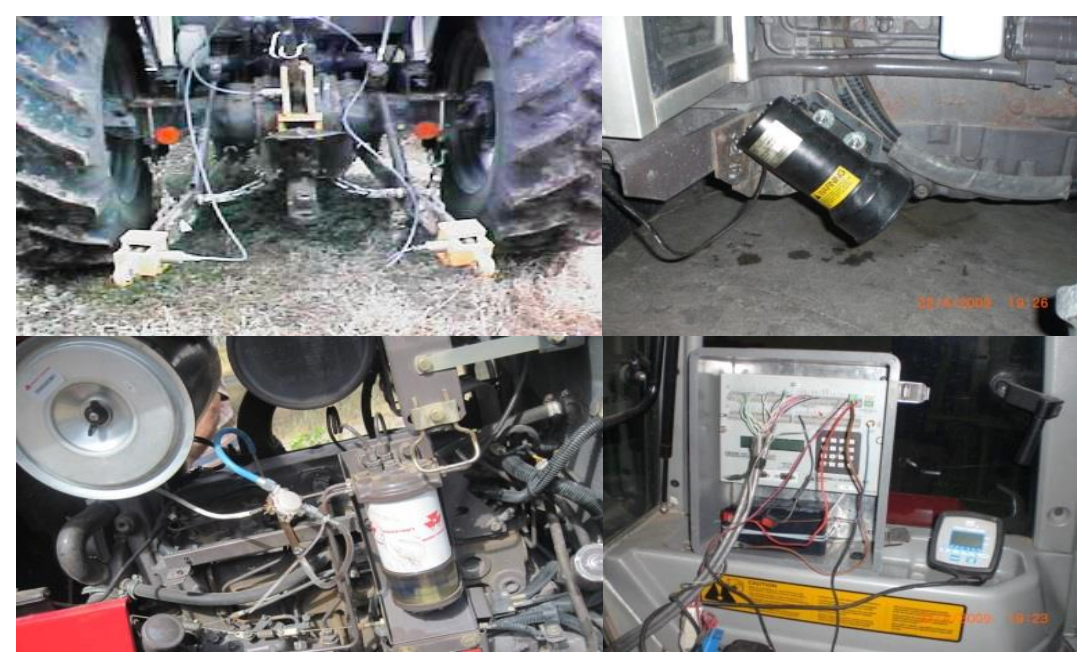

Şekil 3. Güç ölçüm sistemi ve depolama ünitesi

\section{İşletme Değerleri}

Zaman ölçümleri, 1/100 Cmin taksimatlı çift ibreli kronometre ile toplam zaman etütü (Şekil 4) ve iş safhaları eklemeli zaman yöntemiyle ölçülmüş ve zaman etüdü analiz ve değerlendirmeleri Özden
(1995) tarafindan hazırlanan ZET bilgisayar programı kullanılarak yapılmıştır. Kullanılan alet ve makinalarla yapılan zaman etüdü denemelerinde kontrol değeri olarak; $\quad \mathrm{CV} \leq 0.33$ değeri esas alınmıştır. 

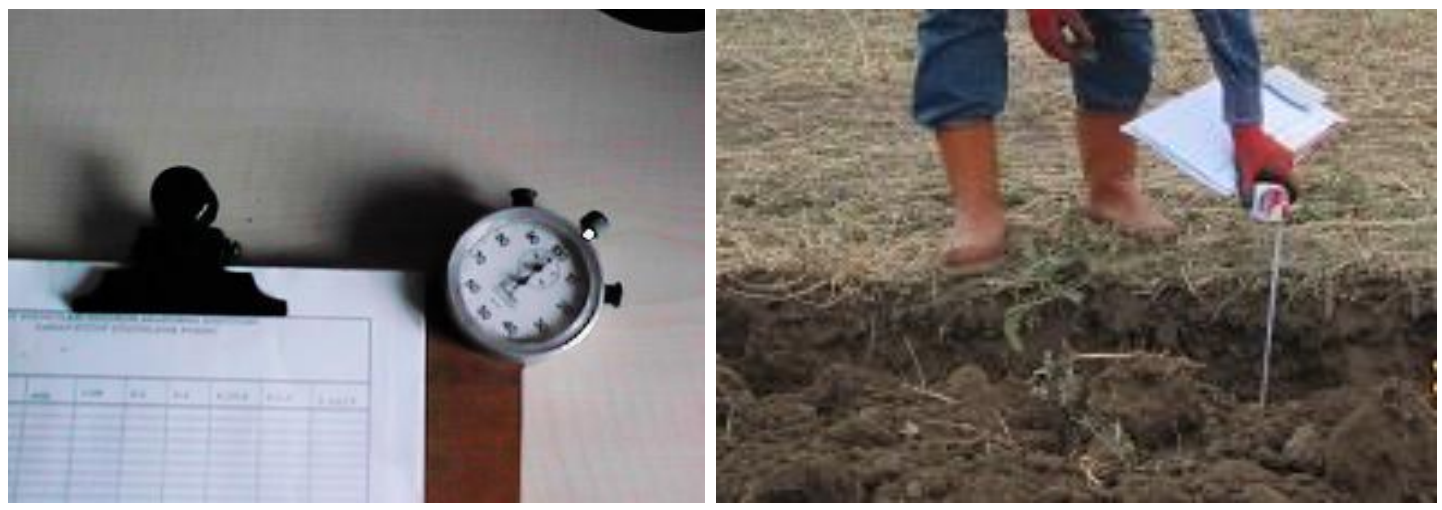

Şekil 4. Zaman etüt tablası ve iş derinliği ölçümü

\section{BULGULAR VE TARTIŞMA}

Yöntemlerin ve yöntemleri oluşturan her bir alet-makinanın sulu ve kuru tarım koşullarında çeki kuvveti-gücü ve yakıt tüketimi değerleri ayrı ayrı belirlenmiş Çizelge 2'de verilmiştir. Sulu ve kuru tarım koşullarında ortalama özgül çeki kuvveti (33.2$\left.35.4 \mathrm{kN} \mathrm{m}^{-2}\right)$, özgül çeki gücü $\left(5.5-5.6 \mathrm{~kW} \mathrm{~m}^{-1}\right)$ ve yakıt tüketimi $\left(26.1-26.3 \mathrm{~L} \mathrm{ha}^{-1}\right)$ değerlerinin birbirine çok yakın olduğu tespit edilmiştir.

Çizelge 2. Toprak işleme-ekim yöntemlerinin yakıt tüketimleri

\begin{tabular}{|c|c|c|c|c|c|c|}
\hline \multirow[t]{2}{*}{ Yöntemler } & \multicolumn{2}{|c|}{$\begin{array}{l}\text { Özgül Çeki Kuvveti } \\
\left(\mathbf{k N ~ m}^{-2}\right)\end{array}$} & \multicolumn{2}{|c|}{ 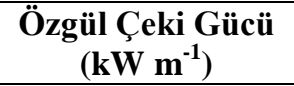 } & \multicolumn{2}{|c|}{$\begin{array}{c}\text { Yakıt Tüketimi } \\
\left(\mathbf{L ~ h a}^{-1}\right)\end{array}$} \\
\hline & Sulu & Kuru & Sulu & Kuru & Sulu & Kuru \\
\hline$S_{1}$ & 63.9 & 72.3 & 13.1 & 13.6 & 46.8 & $\begin{array}{l}47.7 \\
\end{array}$ \\
\hline Pulluk & 34.2 & 33.5 & 8.9 & 7.4 & 25.5 & 23.9 \\
\hline Diskli tırmık+kültivatör & 11.6 & 19.4 & 2.1 & 3.9 & 9.2 & 11.2 \\
\hline Kombikürüm & 14.1 & 15.2 & 1.8 & 1.9 & 6.5 & 6.9 \\
\hline Ekim makinası & 4.0 & 4.1 & 0.3 & 0.4 & 5.5 & 5.7 \\
\hline $\mathbf{S}_{2}$ & 43.5 & 43.2 & 7.0 & 7.0 & 23.6 & 23.0 \\
\hline Kültivatör & 25.5 & 24.7 & 4.9 & 4.9 & 11.2 & 10.4 \\
\hline Kombikürüm & 14.3 & 14.6 & 1.8 & 1.8 & 6.6 & 6.6 \\
\hline Ekim makinası & 3.7 & 3.9 & 0.3 & 0.4 & 5.7 & 5.9 \\
\hline $\mathbf{S}_{3}$ & 13.0 & 14.4 & 1.0 & 1.0 & 24.2 & 24.6 \\
\hline Dik rotovatör & 8.9 & 10.4 & 0.6 & 0.6 & 18.6 & 18.9 \\
\hline Ekim makinası & 4.1 & 4.1 & 0.3 & 0.4 & 5.6 & 5.7 \\
\hline $\mathbf{S}_{4}$ & 12.7 & 11.8 & 0.8 & 0.8 & 9.8 & 10.0 \\
\hline Doğrudan ekim makinası & 12.7 & 11.8 & 0.8 & 0.8 & 9.8 & 10.0 \\
\hline Genel ortalama & 33.2 & 35.4 & 5.5 & 5.6 & 26.1 & 26.3 \\
\hline
\end{tabular}

Geleneksel toprak işleme yönteminin çoğu bölgedeki değişmez tarım aleti pulluğun (her iki tarım koşulunda) özgül çeki kuvveti $\left(33.9 \mathrm{kN} \mathrm{m}^{-2}\right)$ ve özgül güç ihtiyacı $\left(8.2 \mathrm{~kW} \mathrm{~m}^{-1}\right)$ doğrudan ekim yönteminin sırasıyla 2.8 ve 10.3 katını oluşturmuştur. Sulu tarım koşullarında toprak işleme-ekim yöntemlerinin özgül çeki kuvveti ve gücü ortalamaları $\left(33.2 \mathrm{kN} \mathrm{m}^{-2}\right.$ ve $\left.5.5 \mathrm{~kW} \mathrm{~m}^{-1}\right)$, kuru tarım koşullarına göre $\% 6.6$ ve $\% 2.5$ daha az güç ihtiyacı oluşturmuştur.

Her iki tarım koşulunda da en yüksek yakıt tüketimi $24.7 \mathrm{~L} \mathrm{ha}^{-1}$ ile geleneksel toprak işlemenin kaçınılmaz aleti olan pullukta meydana gelmiştir. Bunu, pulluğa göre \%24.1 daha az yakıt tüketen $\mathrm{S}_{3}$ uygulamasinda kullanılan hareketini traktör kuyruk milinden alan dik rotovatör (ortalama $18.7 \mathrm{~L} \mathrm{ha}^{-1}$ ) takip etmiştir. Kullanılan aletler bazında en düşük yakıt tüketimi ise pulluğa göre $\% 76.9$ daha az yakıt tüketen diskli ekim makinasında belirlenmiştir. Yakıt tüketimi açısından anıza doğrudan ekim yöntemi $\left(\mathrm{S}_{4}\right)$ diğer yöntemlere göre avantajlı olarak ön plana çıkmıştır. Benzer sonuçları; Sungur vd. (1994); Kasap vd. (1989); Aykas vd. (2005); Çarman ve Marakoğlu (2008); Gözübüyük vd. (2010)'de elde etmişlerdir.

Sulu ve kuru tarım koşullarında geleneksel toprak işleme yönteminde tüketilen toplam yakıt miktarının $\left(47.3 \mathrm{~L} \mathrm{ha}^{-1}\right) \% 49.3$ 'nü azaltılmış toprak işleme-1'de, \%51.7'ni azaltılmış toprak işleme-2'de ve \%21.0'ni da anıza doğrudan ekim yönteminde 
tüketilmiştir. Birincil ve ikincil toprak işlemede; $\mathrm{S}_{1}$ yöntemleri toplam yakıtın (sulu ve kuru) \%88.288.0'ini, $\mathrm{S}_{2}$ ve $\mathrm{S}_{3}$ yöntemlerinde ise \%74.9 ile $\% 76.8$ 'ini tüketmiştir. Doğrudan ekim yöntemlerinde ise $\left(\mathrm{S}_{4}\right)$ toprak işleme olmayıp, birim alana (ha) toplam 10 litrelik yakıtın tamamı ekimde tüketilmiştir (Çizelge 3). Bu sonuçlar; Anonim (1983)'e göre ABD'de dört farklı toprak işleme yöntemi (geleneksel, azaltılmış toprak işleme-1, azaltılmış toprak işleme-2 ve anıza doğrudan ekim) için yakıt gereksinimlerinin karşılaştırıldığı bir çalışmada elde edilen sonuçlarla sırasıyla, 93.0, 47.1, 31.5 ve $24.1 \mathrm{~L} \mathrm{ha}^{-1}$ benzerlik göstermektedir (Sürek 2004).

Çizelge 3. Toprak işleme-ekim yöntemlerinin yakıt tüketimi değerleri ve oranları

\begin{tabular}{|c|c|c|c|c|c|c|}
\hline Yöntemler & & $\begin{array}{c}\text { Birincil } \\
\text { toprak } \\
\text { işleme }\end{array}$ & $\begin{array}{l}\text { Íkincil } \\
\text { toprak } \\
\text { işleme }\end{array}$ & Ekim & Toplam & $\begin{array}{c}\text { Geleneksel } \\
\text { uygulamaya göre } \\
\text { karşılaştırma }(\%)\end{array}$ \\
\hline \multirow{2}{*}{$\begin{array}{l}S_{1}\left(\mathrm{~L} \mathrm{ha}^{-1}\right) \\
(\%)\end{array}$} & Sulu & $\begin{array}{c}25.5 \\
(54.5)\end{array}$ & $\begin{array}{c}15.8 \\
(33.7)\end{array}$ & $\begin{array}{c}5.5 \\
(11.8)\end{array}$ & 46.8 & 100.0 \\
\hline & Kuru & $\begin{array}{c}23.9 \\
(50.1) \\
\end{array}$ & $\begin{array}{c}18.1 \\
(37.9) \\
\end{array}$ & $\begin{array}{c}5.7 \\
(12.0) \\
\end{array}$ & 47.7 & 100.0 \\
\hline \multirow{2}{*}{$\begin{array}{l}S_{2}\left(\mathrm{~L} \mathrm{ha}^{-1}\right) \\
(\%)\end{array}$} & Sulu & $\begin{array}{c}11.2 \\
(47.6) \\
\end{array}$ & $\begin{array}{c}6.6 \\
(28.0) \\
\end{array}$ & $\begin{array}{c}5.7 \\
(24.3) \\
\end{array}$ & 23.6 & 50.4 \\
\hline & Kuru & $\begin{array}{c}10.4 \\
(45.4) \\
\end{array}$ & $\begin{array}{c}6.6 \\
(28.7) \\
\end{array}$ & $\begin{array}{c}5.9 \\
(25.9) \\
\end{array}$ & 23.0 & 48.2 \\
\hline \multirow{2}{*}{$\begin{array}{l}\mathbf{S}_{3}\left(\mathrm{~L} \mathrm{ha}^{-1}\right) \\
(\%)\end{array}$} & Sulu & $\begin{array}{c}18.6 \\
(76.8)\end{array}$ & - & $\begin{array}{c}5.6 \\
(23.2)\end{array}$ & 24.2 & 51.7 \\
\hline & Kuru & $\begin{array}{c}18.9 \\
(76.7) \\
\end{array}$ & - & $\begin{array}{c}5.7 \\
(23.3) \\
\end{array}$ & 24.6 & 51.7 \\
\hline \multirow{2}{*}{$\begin{array}{l}\mathbf{S}_{4}\left(\mathrm{~L} \mathrm{ha}^{-1}\right) \\
(\%)\end{array}$} & Sulu & - & - & $\begin{array}{c}9.8 \\
(100)\end{array}$ & 9.8 & 20.9 \\
\hline & Kuru & - & - & $\begin{array}{c}10.0 \\
(100)\end{array}$ & 10.0 & 21.0 \\
\hline
\end{tabular}

Farklı toprak işleme-ekim yöntemlerinin özgül çeki kuvveti-gücü, yakıt tüketimi ve bazı işletme parametrelerine etkileri irdelenmiş ve varyans analiz değerleri Çizelge 3.3 'de, ortalama karşılaştırma değerleri ise Şekil 3.1-3.2-3.3 ve 3.4'de verilmiştir. Toprak işleme-ekim yöntemlerinin toprağın özgül çeki kuvveti-gücü, yakıt tüketimi ve bazı işletme değerlerine etkisi, farklı yetiştirme süreçleri (yıl) ve farklı tarım koşullarında (sulu-kuru) $\quad \mathrm{P}<0.01$ düzeyinde önemli farklılıklar oluşturmuştur.

En yüksek güç ve yakıt tüketim değerleri geleneksel toprak işleme-ekim yöntemlerinde ortalama olarak (sulu+kuru) $68.1 \mathrm{kN} \mathrm{m}^{-2}, 13.3 \mathrm{~kW} \mathrm{~m}^{-}$ ${ }^{1}$ ve $47.2 \mathrm{~L} \mathrm{ha}^{-1}$ bulunmuştur. En düşük değerler ise toprağı işlemeden doğrudan ekim uygulamasından elde edilmiş ve geleneksel uygulamaya göre $\% 82$ özgül çeki kuvveti, \%94.1 özgül çeki gücü ve $\% 79$ daha düşük yakıt tüketim değerleri elde edilmiştir. Uygulamalar arasında kullanılan alet makina sayısı azaldıkça buna bağlı olarak özgül çeki kuvveti-gücü ve yakıt tüketim değerleri de azalmıştır (Şekil 3.1-
3.2). Buğday üretiminde geleneksel uygulamada birim alandan (ha) ortalama 63.2 litre yakıt tüketimi olurken, azaltılmış toprak işlemede 22.8, doğrudan ekimde ise 10 litreye kadar düşmektedir (Anonim, 2011). İkinci ürün pamuk üretiminde doğrudan ekim uygulama olanaklarının belirlendiği çalışmada da benzer sonuçlar elde edilmiştir (Aykas vd., 2006).

Sulu ve kuru tarım koşullarında ortalama olarak efektif iş başarıları, geleneksel toprak işleme yönteminde 0.127 ha $\mathrm{h}^{-1}$ olurken, doğrudan ekim yönteminde 4.9 kat $\left(0.624 \mathrm{ha} \mathrm{h}^{-1}\right), \mathrm{S}_{3}$ yönteminde $2.25 \mathrm{~kat}\left(0.278 \mathrm{ha} \mathrm{h}^{-1}\right)$ ve $\mathrm{S}_{2}$ yönteminde de $2.10 \mathrm{~kat}$ $\left(0.298 \mathrm{ha} \mathrm{h}^{-1}\right)$ daha fazla alan işlenerek zamansal olarak oldukça önemli avantaj elde edilmiştir (Şekil 3.3-3.4). Böylece, tarımla uğraşanların mevsime bağlı tarımsal işlemleri zamanında bitirerek diğer çiftlik işlerine daha fazla zaman ayırmasına imkân sağlanmış olacaktır. Benzer sonuçlar Kasap vd. (1989); Aykas vd. (2005); Çarman ve Marakoğlu (2008); Gözübüyük vd. (2010) tarafından yapılan çalışmalarda da tespit edilmiştir. 
Çizelge 4. İşletme parametrelerinin varyans analizi değerleri

\begin{tabular}{|c|c|c|c|c|c|c|}
\hline \multirow[b]{2}{*}{ Parametreler } & \multirow[b]{2}{*}{$\begin{array}{l}\text { Varyasyon } \\
\text { Kaynakları }\end{array}$} & \multirow[b]{2}{*}{$\begin{array}{c}\text { Serbestlik } \\
\text { Derecesi }\end{array}$} & \multicolumn{2}{|c|}{ Sulu Tarım } & \multicolumn{2}{|c|}{ Kuru Tarım } \\
\hline & & & $\begin{array}{l}\text { Kareler } \\
\text { Toplamı }\end{array}$ & $\mathbf{F}$ & $\begin{array}{l}\text { Kareler } \\
\text { Toplamı }\end{array}$ & $\mathbf{F}$ \\
\hline \multirow{3}{*}{$\begin{array}{l}\text { Özgül çeki } \\
\text { kuvveti } \\
\left(\mathrm{kN} \mathrm{m}^{-2}\right)\end{array}$} & Yil & 2 & 206.93 & $43.01 * *$ & 76.33 & $9.53 * *$ \\
\hline & TiY & 3 & 16890.94 & $2340.35^{* *}$ & 21739.19 & $1808.65 * *$ \\
\hline & Blok & 2 & 12.48 & 2.59 & 4.29 & 0.54 \\
\hline \multirow{3}{*}{$\begin{array}{l}\text { Özgül çeki } \\
\text { gücü } \\
\left(\mathrm{kW} \mathrm{m}^{-1}\right)\end{array}$} & Y1l & 2 & 0.17 & 0.49 & 1.58 & 1.39 \\
\hline & TIYY & 3 & 927.88 & $1813.06^{* *}$ & 984.27 & $576.62 * *$ \\
\hline & Blok & 2 & 1.07 & 3.14 & 0.45 & 0.40 \\
\hline \multirow{3}{*}{$\begin{array}{l}\text { Yakıt } \\
\text { Tüketimi } \\
\left(\mathrm{L} \mathrm{ha}^{-1}\right)\end{array}$} & Y11 & 2 & 13.84 & $25.05^{* *}$ & 27.65 & $31.33^{* *}$ \\
\hline & TiY & 3 & 6325.31 & $7630.27 * *$ & 6628.25 & $5007.83 * *$ \\
\hline & Blok & 2 & 0.44 & 0.80 & 1.63 & 1.85 \\
\hline \multirow{3}{*}{$\begin{array}{l}\text { İnsan işgücü } \\
\text { (İnsan-h ha }^{-1} \text { ) }\end{array}$} & Y1l & 2 & 23.42 & $81.83 * *$ & 19.39 & $49.73 * *$ \\
\hline & TİY & 3 & 188.45 & $438.94 * *$ & 222.76 & $380.87 * *$ \\
\hline & Blok & 2 & 0.24 & 0.83 & 0.51 & 1.31 \\
\hline \multirow{3}{*}{$\begin{array}{l}\text { Makina } \\
\text { işgücü } \\
\left(\text { Makina-h ha }{ }^{-1}\right)\end{array}$} & Y1l & 2 & 15.25 & 89.66 ** & 12.27 & $41.81 * *$ \\
\hline & TİY & 3 & 190.15 & $745.39 * *$ & 220.86 & $501.78 * *$ \\
\hline & Blok & 2 & 0.06 & 0.38 & 0.33 & 1.13 \\
\hline \multirow{3}{*}{ 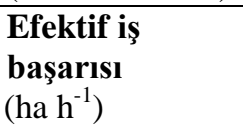 } & Y11 & 2 & 0.06 & $31.51 * *$ & 0.09 & $114.44 * *$ \\
\hline & TiY & 3 & 1.08 & $361.84 * *$ & 1.29 & $1138.65 * *$ \\
\hline & Blok & 2 & 0.00 & 0.53 & 0.00 & 0.57 \\
\hline
\end{tabular}

** $\mathrm{P}<0.01$ düzeyinde önemli, TİY: Toprak İşleme Yöntemleri

İşlenen birim alan başına makina ve insan işgücü ihtiyacı açısından anıza doğrudan ekim yönteminden her iki tarım koşulunda da diğer yöntemlere göre oldukça düşük işgücü ihtiyacı değerleri elde edilmiş, özellikle makina işgücü ihtiyacında bu farkın daha belirgin şekilde olduğu saptanmıştır. Geleneksel toprak işleme-ekim yönteminde bir hektar alanın işlenmesi ve ekimi için 8.13 saat makina işgücüne ihtiyaç varken, anıza doğrudan ekim yönteminde bu işlemler 4.98 kat daha az bir zamanda (1.63 saatte) yapılabilmektedir. İnsan işgücü ihtiyacında da benzer durum oluşmuş, bir hektar alanın işlenmesi ve ekimi için 9.74 saat insan işgücüne ihtiyaç varken, anıza doğrudan ekim yönteminde 3.48 saat yeterli olmuştur. Yapılan birçok araştırmada azaltılmış toprak işleme yöntemlerinde de geleneksel toprak işlemeye göre yarıya yakın işgücü tasarrufu belirlenmiştir (Karaağaç ve Barut, 2007; Kumar vd., 2013).

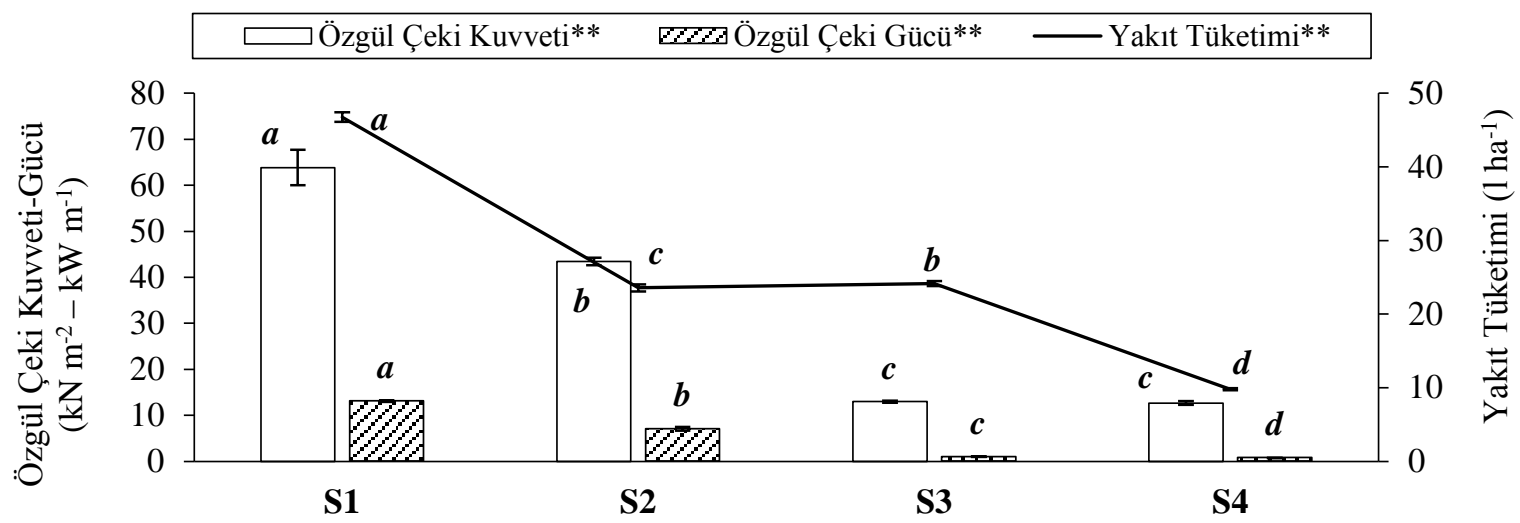

Toprak İşleme Yöntemleri

** $\mathrm{P}<0.01$ düzeyinde önemli; $\mathrm{S}_{1}$ : Geleneksel toprak işleme, $\mathrm{S}_{2}$ :Azaltılmış toprak işleme-1, $\mathrm{S}_{3}$ :Azaltılmış toprak işleme-2, $\mathrm{S}_{4}$ :Doğrudan ekim

Şekil 5. Sulu tarım koşullarında özgül çeki kuvveti-gücü ve yakıt tüketimi değerlerinin ortalama karşılaştırma sonuçları 


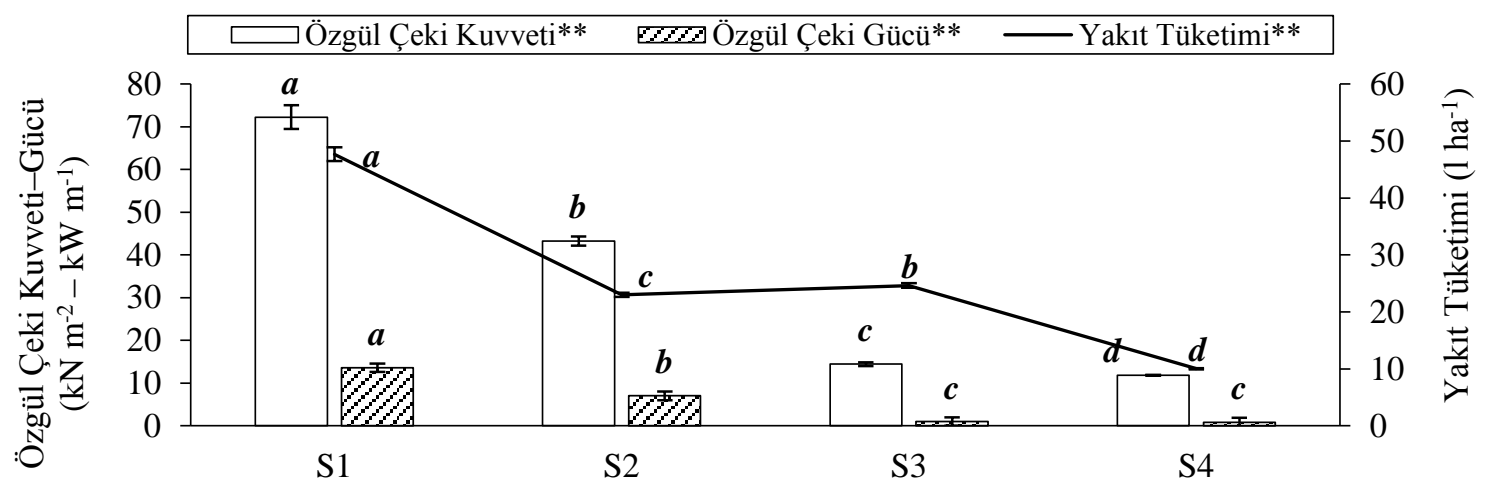

Toprak İşleme Yöntemleri

** $\mathrm{P}<0.01$ düzeyinde önemli; $\mathrm{S}_{1}$ :Geleneksel toprak işleme, $\mathrm{S}_{2}$ :Azaltılmış toprak işleme-1, $\mathrm{S}_{3}$ :Azaltılmış toprak işleme-2, $\mathrm{S}_{4}$ :Doğrudan ekim Şekil 6. Kuru tarım koşullarında özgül çeki kuvveti-gücü ve yakıt tüketimi ortalama karşılaştırma sonuçları

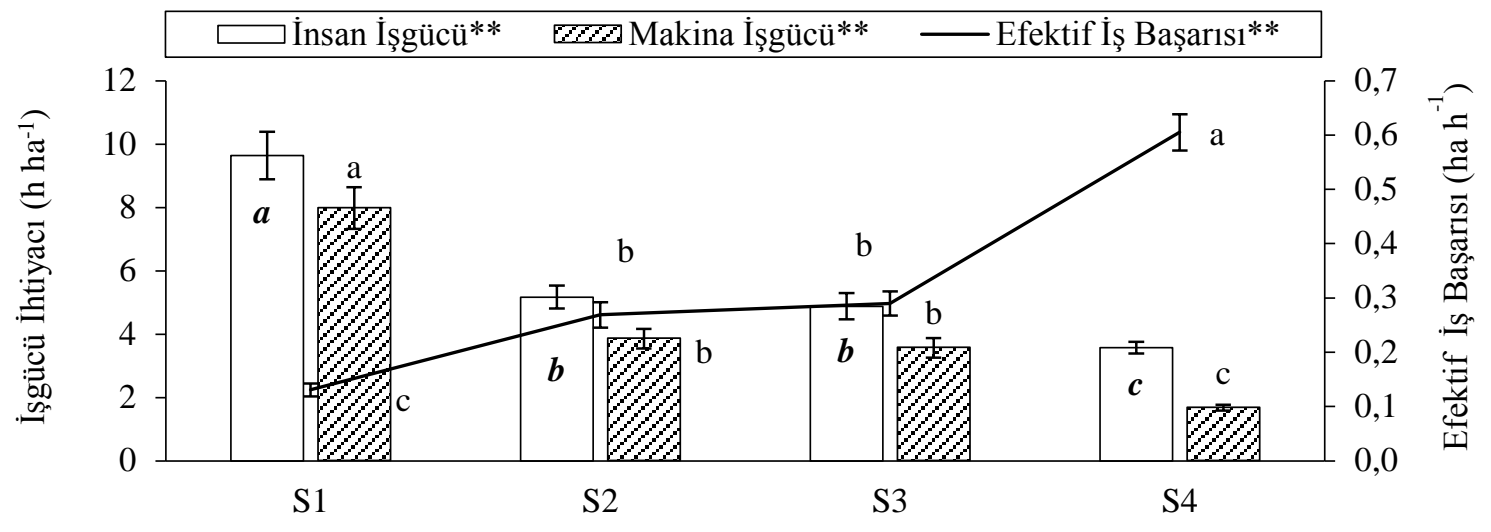

Toprak İşleme Yöntemleri

** $\mathrm{P}<0.01$ düzeyinde önemli; $\mathrm{S}_{1}$ :Geleneksel toprak işleme, $\mathrm{S}_{2}$ :Azaltılmış toprak işleme-1, $\mathrm{S}_{3}$ :Azaltılmış toprak işleme-2, $\mathrm{S}_{4}$ : Doğrudan ekim

Şekil 7. Sulu tarım koşullarında insan-makina işgücü ihtiyacı ve efektif iş başarıları ortalama karşılaştırma sonuçları

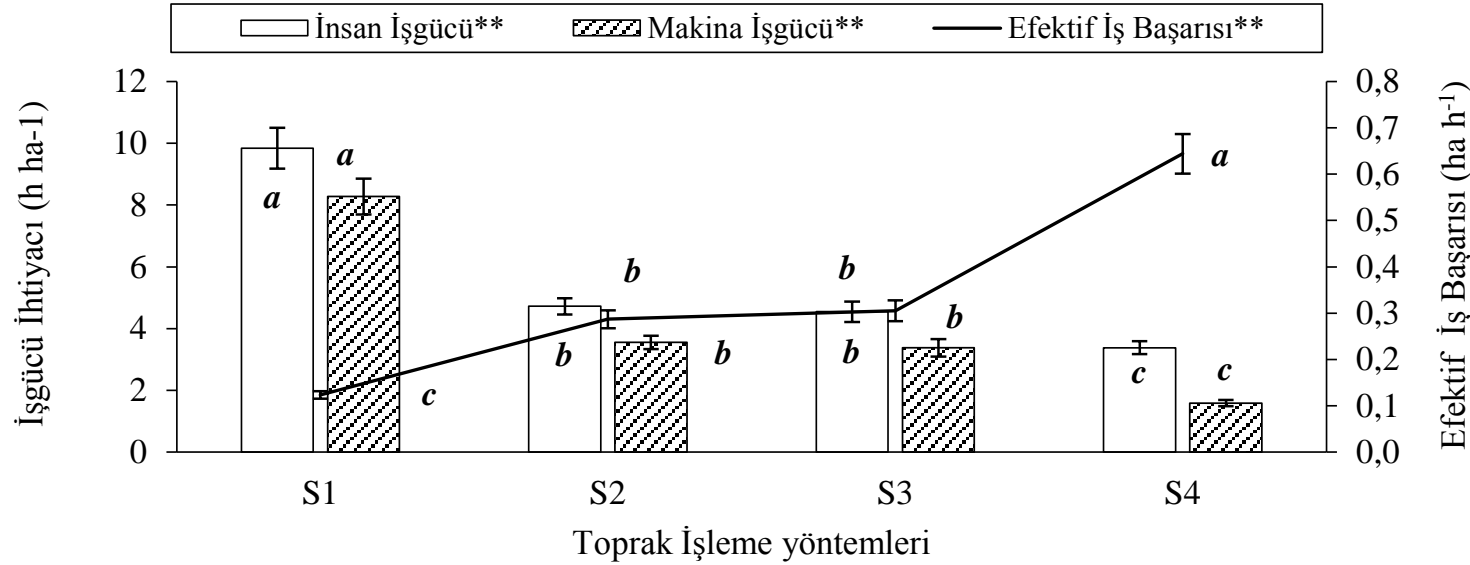

** $\mathrm{P}<0.01$ düzeyinde önemli; $\mathrm{S}_{1}$ : Geleneksel toprak işleme, $\mathrm{S}_{2}$ :Azaltılmış toprak işleme-1, $\mathrm{S}_{3}$ :Azaltılmış toprak işleme-2, $\mathrm{S}_{4}$ :Doğrudan ekim

Şekil 8. Kuru tarım koşullarında insan-makina işgücü ihtiyacı ve efektif iş başarısı değerlerinin ortalama karşılaştırma sonuçları 


\section{SONUÇLAR}

Yüksek rakımda ve yarı kurak iklim koşullarında 9 yıl süren araştırmanın üç yılını oluşturan fiğ üretiminde; kuru tarım koşullarında özgül çeki kuvvetinin $\% 6.2$, özgül çeki gücünün $\% 1.8$ ve yakıt tüketiminin $\% 0.8$ sulu tarım koşullarına göre daha yüksek olduğu, bunun da topraktaki nem düşüklüğüne bağlı olarak arttığı tespit edilmiştir. Her iki tarım koşulunda da özgül çeki kuvveti, özgül çeki gücü ve yakıt tüketimi açısından doğrudan ekim konusundan, diğer uygulamalara göre daha iyi sonuçlar elde edilmiştir. Geleneksel uygulama en yüksek güç ve kuvvet gereksinimlerini oluşturmuş, bunu $\mathrm{S}_{3}, \mathrm{~S}_{2}$ ve en düşük değerle (13.7 kN $\mathrm{m}^{-2}$ ve $1.0 \mathrm{~kW} \mathrm{~m} \mathrm{~m}^{-1}$ ) doğrudan ekim uygulaması takip etmiştir. Tükenmekte olan fosil kaynaklı yakıt kullanımını ve erozyonu azaltan, toprak nemini koruyan koruyucu toprak işleme-ekim yöntemlerinin kullanılması kaçınılmazdır. Bölge ve toprak yapısına bağlı olarak yakıt tüketimi, insan ve makina işgücü gereksinimleri yönünden avantajlı olan anıza doğrudan ekim $\left(\mathrm{S}_{4}\right)$ ve/veya azaltılmış toprak işleme-ekim uygulamalarının yapılması önerilebilir.

$\mathrm{Bu}$ çalışmada hem sulu hem de kuru toprak şartlarında, doğrudan ve azaltılmış toprak işlemeekim yöntemlerinde geleneksel uygulamaya göre birim zamanda daha fazla alan işlenerek zaman açısından oldukça önemli bir avantaj elde edilmiştir. Özellikle ikinci ürün üretimi yapılabilen bölgelerde zaman ve işgücü açısından oldukça avantajlı olan doğrudan ekim ve azaltılmış toprak işleme-ekim yöntemleri önerilebilir. Özellikle, üretim girdilerinde en fazla orana sahip olan tarım makinalarının ve insan işgücü ihtiyacını azaltan doğrudan ekim uygulamalarıla, zaman ve kaynaklar etkin bir şekilde kullanılabilecek ve bu şekilde ülke ekonomisine önemli oranda katkılar sağlanabilecektir.

\section{KAYNAKLAR}

Aase, J.K., Schaefer, G.M., 1996. Economics of tillage practices and spring wheat and barley crop sequence in northern great plains. J. Soil Water Conserv. 51: 167-170.

Anonim, 1983. Fundamentals of no-till farming. American associations for vocational instructional materials. Driftmier Engineering Center Athens, GA 30602

Anonim, 2011. Ulusal Hububat Konseyi Buğday Raporu. Mayıs, 2011. http://uhk.org.tr/ dosyalar /bugdayraporumayis2011.pdf (23.10.2016)

Aykas, E., Yalçın, H., Çakır, E., 2005. Koruyucu toprak işleme yöntemleri ve doğrudan ekim. Ege Üniv. Ziraat Fak. Derg., 42(3): 195-205.

Aykas, E., Yalçın, H., Önal, İ., Evcim, Ü., 2006. İkinci ürün pamuk üretiminde doğrudan ekim uygulama olanakları. Proje Kesin Sonuç Raporu. Türkiye Bilimsel Teknik Araştırma Kurumu. Proje No: Tovag, 2675.

Çarman, K., Marakoğlu, T., 2008. Buğday üretiminde azaltılmış toprak işleme ve direk ekim uygulamaları. Selçuk Üniv. Ziraat Fak. Derg., 22 (46): 73-76.
Çarman, K., Öğüt, H., Hacıseferoğulları, H., 1995. Konya bölgesinde buğday tarımında uygulanan farklı toprak işleme yöntemlerinin toprak özellikleri, enerji tüketimi ve buğdayın verim parametreleri üzerine etkisi. Tarımsal Mekanizasyon 16. Ulusal Kongresi, s:110-119, Bursa.

Derpsch, R., Friedrich, T., Kassam, A., Li H., 2010. Current status of adoption of no-till farming in the world and some of its main benefits. International Journal of Agricultural and Biological Engineering, 3(1), 1-25.

Eker, B., Ülger, P., 1988. Ayçiçeği tarımında kullanılan toprak işleme aletlerinin toprak ve bitki karakteristiklerine etkilerinin araştırılması. Tarımsal Mekanizasyon 11. Ulusal Kongresi. 10-12 Ekim 1988. Erzurum, Türkiye.

FAO, 2014. http://www.fao.org. (28.07.2017).

FAO AQUASTAT, 2014. http://www.fao.org/nr/aquastat/. (Erişim: 28.07.2017).

Gökçebay, B., 1983. Minimum Toprak İşleme Tekniği. TZDK Mesleki Yayınları. Ankara.

Gözübüyük, Z., Öztürk, İ., Demir, O., Çelik, A., 2010. Ayçiçeğinde farklı toprak işleme-ekim sistemlerinin bazı işletme parametreleri yönünden karşıllaştırılması. Tarım Makinaları Bilimi Dergisi, 6 (4), 253-259.

Griffith, D.R., Parsons, S.D., 1981. Energy requipments for various tillage-planthing systems. (Tillage) Id-141, Coop. Ext. Ser. Purdue Uni, Indiana.

Karaağaç, H.A., Barut, Z.B., 2007. İkinci ürün silajlık mısır tarımında farklı toprak işleme ve ekim yöntemlerinin teknik ve ekonomik yönden karşılaştırılması. Tarım Makinaları Bilimi Dergisi 3 (1), 33-40.

Kasap, A., Ergüneş, G., Erdem, G., 1989. Bazı tarım iş makinaları kombinasyonları ile çalışmada zaman, yakıt ve enerji tasarrufunun incelenmesi. Tarımsal Mekanizasyon 12. Ulusal Kongresi, 1-2 Haziran 1989, Tekirdağ.

Kumar, V., Saharawat, Y.S., Gathala, M.K., Jat, A.S., Singh, S.K., Chaudhary, N., Jat, M.L., 2013. Effect of different tillage and seeding methods on energy use efficiency and productivity of wheat in the Indo-Gangetic Plains. Field Crops Research, 142, 1-8.

Lazic, V., Turan, J., 1995. Factors of fuel consumption in ploughing. Contemporary agricultural engineering. 21(1) 54-60.

Özden, D.M., 1995. Tarımsal Mekanizasyonda Zaman Etüdü Çözümleme (ZET) ve Veri Tabanı Olușturma Bilgisayar Programı, (Kitap) Köy Hizmetleri Genel Müdürlüğü A.P.K Dairesi Başkanlığı. Toprak ve Su Kaynakları Araştırma Şube Müdürlüğü. Yayın No: 82.

Özgüven, F., 1993. Kuyruk milinden hareketli, dönerek çalışan bazı toprak işleme makinalarının toprağa yaptığı bazı fiziksel etkiler ile iş yetikliği açısından kıyaslanması üzerine bir araştırma. 5. Uluslararası Tarımsal Mekanizasyon ve Enerji Kongresi Bildiri Kitabı, s:102-110, Kuşadası.

Özsert, İ., Kara, M., 1987. Kuru tarım tahıl üretiminde değişik toprak işleme-ekim sistemleri ve enerji gereksinimleri. 3.Uluslararası Tarımsal Mekanizasyon ve Enerji Simpozyumu. s: 238-247, 26-29 Ekim, İzmir.

Sungur, N., Rux, S., Yalçın, H., 1993. Suitability of direct-sowing systems for the conditions of western Turkey. 5. Uluslararası Tarımsal Mekanizasyon ve Enerji Kongresi, Bildiri Kitabı. s: 226-236, 12-14 Ekim, Kuşadası.

Sungur, N., Ulusoy, E., Yalçın, H., 1994. Ege bölgesi koşullarında buğday ve ikinci ürün misır elde etmede mekanizasyon olanakları, Tarımsal Mekanizasyon 15. Ulusal Kongresi Bildiri Kitabı. s: 582-591, Antalya.

Sürek, D., 2004. Kuru tarımda farklı ekim nöbeti uygulama etkinliklerinin karşılaştırılması. Ankara Üniversitesi, Fen Bilimleri Enstitüsü. Doktora Tezi, Toprak Anabilim Dalı.

Zeren, Y., 1991. AT Ülkelerinde tarımsal yap1, mekanizasyon ve enerji kullanımı. Tarımsal Mekanizasyon 13. Ulusal Kongresi, 98-120, Konya. 